\title{
La investigación etnomusicológica en México, ¿legítimos tiempos de transformación o perenne austeridad institucional?
}

Carlos Ruiz Rodríguez

Instituto Nacional de Antropología e Historia, Ciudad de México, México ruiroca@hotmail.com

Recepción: septiembre 2020. Aceptación: diciembre 2020.

\section{Resumen}

En 2018, con la llegada al poder gubernamental de uno de los partidos políticos que presumía ideología política de izquierda, México vislumbraba un tiempo de profundos cambios que incidieran en la sociedad y en la propia configuración del Estado mexicano. Las políticas neoliberales de las últimas tres décadas habían intensificado graves problemas nacionales como la corrupción, la pobreza, la inseguridad y la violencia de género. En ese contexto, el plan del nuevo gobierno para transformar el país postulaba al sector cultural como importante eje de recuperación del tejido social. Sin embargo, los recortes presupuestales impuestos por el actual gobierno a ese sector distan de poder convertirle en el deseado "eje transformador" que se planteaba. El presente escrito ofrece un panorama de las condiciones actuales de la investigación etnomusicológica en el ámbito cultural institucional en relación con las políticas culturales del Estado y del lugar que ocupa esta disciplina en el seno académico. El acercamiento se enfoca en los desafíos que se presentan a la investigación etnomusicológica en la actual coyuntura política de las instituciones públicas y en el importante papel que desde hace veinte años ha adquirido la investigación musical realizada por centros de investigación y universidades estatales.

Palabras clave: etnomusicología en México, política cultural, instituciones de cultura 


\title{
Pesquisa etnomusicológica no México, tempos legítimos de transformação ou austeridade institucional perene?
}

\section{Resumo}

Em 2018, com a chegada ao governo de um dos partidos políticos que presumiam ideologia política de esquerda, o México previu um período de profundas mudanças que afetariam a sociedade e a própria configuração do Estado mexicano. As políticas neoliberais das últimas três décadas intensificaram sérios problemas nacionais como corrupção, pobreza, insegurança e violência de gênero. Nesse contexto, o plano do novo governo de transformar o país postulou o setor cultural como um importante eixo de recuperação do tecido social. No entanto, os cortes financeiros impostos pelo atual governam a esse setor está longe de transformá-lo no desejado "eixo transformador" proposto. Este artigo oferece uma visão geral das condições atuais da pesquisa etnomusicológica na esfera cultural institucional em relação às políticas culturais do Estado, e o lugar que essa disciplina ocupa no campo acadêmico. A abordagem enfoca os desafios apresentados à pesquisa etnomusicológica na atual situação política das instituições públicas e o importante papel que a pesquisa musical realizada por centros de pesquisa e universidades estaduais adquire há vinte anos.

Palavras-chave: Etnomusicologia no México, política cultural, instituções culturais

\section{Ethnomusicological Research in Mexico: Legitimate Times of Transformation or Perennial institutional Austerity?}

\begin{abstract}
In 2018, with the arrival to government of one of the political parties that presumed left-wing political ideology, Mexico envisioned a time of profound changes that would affect society and the very configuration of the Mexican State. The neoliberal policies of the last three decades had intensified serious national problems such as corruption, poverty, insecurity and gender violence. In this context, the new government's plan to transform the country postulated the cultural sector as an important axis of recovery of the social fabric. However, the budget cuts imposed by the current government on this sector prevent it from being able to turn it into the desired "transforming axis" that was proposed. This paper offers an overview of the current conditions of ethnomusicological research in
\end{abstract}


the institutional cultural sphere in relation to the cultural policies of the State and the place that this discipline occupies in the academic field. The approach focuses on the challenges ethnomusicological research faces in the current political situation of public institutions, and on the important role that music research carried out by research centers and state universities has acquired in the last twenty years.

Keywords: Ethnomusicology in Mexico, political culture, cultural institutions

En 2018, tras las elecciones presidenciales y de gubernaturas estatales, México optó por un cambio de régimen político. La decisión no fue fácil, la sociedad se había polarizado durante la contienda electoral, pero al final ganó la clama por combatir la corrupción y la inseguridad, vistos como los dos males que más aquejaban al país. El partido político de mayor aceptación (Movimiento de Regeneración Nacional, o MORENA), que presumía una ideología política de izquierda, superó por mucho a los dos partidos políticos adversarios que presentaban mayor competencia (Partido Revolucionario Institucional y Partido Acción Nacional), quienes fueron responsables de conducir la política económica del país por una senda neoliberal durante las últimas tres décadas. No obstante, acorde a las propuestas de las campañas políticas, cualquiera de las opciones en contienda carecía de un proyecto claro en torno al tema cultural. En el caso específico de MORENA, partido que planteaba efectuar la llamada Cuarta Transformación del país (siguiendo tres momentos coyunturales de la historia mexicana: Independencia, Reforma y Revolución), la agenda de cambio apuntaba a que la cultura no volvería a ser accesoria en el plan de desarrollo nacional, sino que sería un eje rector para la regeneración del dañado tejido social. Sin embargo, en el escenario actual, ese objetivo dista mucho de poder lograrse, pues otras prioridades de la presente administración, en conjunción con los agudos recortes presupuestales al sector cultural, sumen a este importante "eje transformador" en la incertidumbre.

Si bien todavía es temprano para evaluar una deseada transformación política y económica que comienza, en el escenario de un nuevo régimen de gobierno y tras el impacto generado por la pandemia del COVID-19, pueden vislumbrarse pocos cambios para la precariedad de la investigación etnomusicológica. ${ }^{1}$ No solo eso, puede preverse incluso la disminución de los ya escasos espacios laborales destinados a este quehacer en el futuro inmediato. Basado en datos empíricos, entrevistas de campo, información

${ }^{1}$ Utilizo en este escrito al término "etnomusicológico" para referirme de manera generalizada a los estudios centrados en las llamadas músicas "tradicionales" y "populares". 
de fuentes oficiales y algunos reportes periodísticos, el presente escrito ofrece un panorama de las condiciones actuales de la investigación etnomusicológica en el ámbito cultural institucional y el lugar que ocupa esta disciplina en el seno de las ciencias sociales y las humanidades. El acercamiento se enfoca en los desafíos que se presentan a la investigación etnomusicológica en la actual coyuntura política de las instituciones públicas, y en el importante papel que desde hace veinte años ha adquirido la investigación musical realizada por centros de investigación y universidades estatales.

\section{Política cultural e investigación musical en perspectiva histórica}

Como bien señala Miguel Ángel García, "en Latinoamérica las investigaciones sobre música -en todas sus vertientes- están al amparo del Estado. $\mathrm{Si}$, excepcionalmente, prosperan en instituciones privadas, éstas suelen gozar de manera directa o indirecta de beneficios estatales" (2016, p. 1). El caso mexicano no es la excepción. Por lo menos entre 1919 y los albores del presente siglo, el papel del Estado como promotor de la investigación musical ha sido fundamental. Sin embargo, si se revisa históricamente el desarrollo del campo podrá advertirse que el auge del folklore musical y el surgimiento posterior de la llamada etnomusicología tienen lugar en el seno de políticas culturales institucionales que no son fortuitas. Históricamente, los gobiernos mexicanos han brindado apoyo a los estudios, del ahora llamado patrimonio musical, casi exclusivamente en función de intereses políticos e ideológicos. La propia denominación de la materia de estudios, identificada primero como folklore musical (1919-1968), luego, como música tradicional (1968-2003) y hoy como patrimonio musical (2003-2019), da cuenta de la relación perenne entre política e investigación musical.

De manera esquemática puede decirse que, durante el segundo tercio del siglo XX, el estudio del folklore musical fue favorecido principalmente para acercar insumos a la música de arte académica de corte nacionalista, así como para colaborar a consolidar el proyecto ideológico de nación del México posrevolucionario. Más tarde, durante los años setenta, la investigación etnomusicológica emergió como resultado coyuntural de una política que fomentaba la revaloración de las culturas populares, recurso distractor ante la crisis económica de mediados de esa década. El surgimiento institucional de las llamadas "fonotecas" como instancias de estudio, preservación y divulgación de las expresiones musicales 
"tradicionales" no habría ocurrido sin los gobiernos de los setenta e inicios de los ochenta, los cuales buscaron nuevos contenidos de revaloración del folklore musical mediante el "rescate" y registro fonográfico, ante el desgaste esquemático del folclorismo nacionalista representado en los ballets folclóricos y las obras musicales de corte nacionalista (Ruiz, 2015). El retorno al folklore musical de estos años colaboró a obnubilar los grandes problemas políticos y sociales que detonaron la guerrilla rural y urbana de los años setenta ("guerra sucia") y la grave crisis económica de los años ochenta que llevó a México a estar entre los países más endeudados del mundo (Toussaint, 2006).

De 1988 a 2018, en el marco de una sucesión de gobiernos neoliberales y la adhesión de México a la Convención para la Salvaguarda del Patrimonio Inmaterial de la UNESCO (en 2005), la materia de estudio paulatinamente tomó el nombre de "patrimonio musical", término apropiado para el vínculo político entre cultura y desarrollo. Varias investigaciones han señalado cómo ese vínculo busca la declaratoria de expresiones músico-dancísticas como elementos de la Lista representativa del patrimonio cultural inmaterial de la UNESCO, con el propósito velado de legitimar expresiones culturales que aporten, en calidad de "bienes" o "recursos culturales", a apuntalar circuitos turísticos que contribuyan al desarrollo económico (Flores, 2014; Sevilla, 2014; Martínez Ayala, 2017). Desde 2003, México ha sido uno de los países más activos en elaborar y proponer expedientes para la lista representativa de la UNESCO, donde actualmente tiene inscritas cuatro expresiones músico-dancísticas.

Pese a estos vaivenes de las políticas culturales del Estado la investigación etnomusicológica se mantuvo inercialmente activa hasta fines del siglo XX. No obstante, en los últimos veinte años, este ramo de investigación ha declinado paulatinamente al grado de haber desaparecido en algunas instancias del aparato cultural gubernamental. En ese sentido, conviene ahondar de manera más específica en dónde se ha desarrollado la investigación etnomusicológica institucional y con qué grado de apoyo y legitimidad ha contado en sus ámbitos de desarrollo durante los últimos veinte años.

\section{El apoyo a la investigación etnomusicológica institucional en los últimos veinte años}

En México se hace investigación etnomusicológica en una diversidad de instancias e iniciativas que van desde las becas en Programas de posgrado en algunas universidades hasta proyectos apoyados por fondos de apoyo 
a las culturas comunitarias y programas sociales. No obstante, aquí solo me centraré en el apoyo que ofrece el Estado mexicano a la investigación etnomusicológica en sus instituciones culturales de orden nacional (y que dependen financieramente del presupuesto público), para dimensionar el interés oficial en este campo de estudio. ${ }^{2}$ Las instituciones del Estado mexicano en las que ha estado presente la investigación etnomusicológica son cinco: el Instituto Nacional de Bellas Artes y Literatura (INBAL), el Instituto Nacional de Antropología e Historia (INAH), la Dirección General de Culturas Populares, Indígenas y Urbanas (DGCPIU), el Instituto Nacional de los Pueblos Indígenas (INPI, antes Comisión Nacional de los Pueblos Indígenas, y previamente Instituto Nacional Indigenista) y la Universidad Nacional Autónoma de México (UNAM). Las primeras tres dependen de la Secretaría de Cultura, la cuarta se adscribe directamente al poder ejecutivo federal, mientras que la UNAM goza de autonomía al margen de los poderes ejecutivo, legislativo y judicial. El papel de estas cinco instituciones en el quehacer etnomusicológico ha sido fundamental, por lo menos hasta hace veinte años en que el carácter centralista del gobierno mexicano comenzó paulatinamente a diluirse y la investigación musical en los estados del interior de la República mexicana tomó mayor presencia disciplinar.

El más antiguo e importante centro de investigación en México es el Centro Nacional de Investigación, Documentación e Información Musical Carlos Chávez (CENIDIM) del Instituto Nacional de Bellas Artes y Literatura (INBAL). El CENIDIM fue fundado en 1974, aunque hunde sus precedentes tres décadas atrás en la antigua Sección de Investigaciones del INBA (Cortéz, 2016). Desde sus inicios el CENIDIM ha mantenido una labor enfocada en la música produciendo una gran cantidad de conocimiento académico a la par de divulgación de materiales y preservación de acervos. En los últimos quince años destaca la permanencia de la Cátedra Jesús C. Romero que anualmente invita a un reconocido investigador especialista en la música mexicana o iberoamericana, quien ofrece conferencias magistrales, dirige un seminario de investigación y organiza una mesa redonda.

Si bien el CENIDIM se encuentra adscrito al máximo órgano artístico del Estado, el Instituto Nacional de Bellas Artes, eso no quiere decir que goce de una infraestructura y presupuesto suficiente. De acuerdo con uno de sus

${ }^{2}$ No incluyo aquí la importante labor etnomusicológica efectuada en Centros de investigación financiados por el Consejo Nacional de Ciencia y Tecnología por no entrar en el perfil de "instituciones nacionales", como el Centro de Investigaciones y Estudios Superiores en Antropología Social, El Colegio de México, El Colegio de la Frontera Norte, El Colegio de Michoacán, El Colegio de San Luis y El Colegio de la Frontera Sur, entre otros; sin embargo, recuperaré su papel hacia el final de este escrito. 
investigadores fundadores, Hiram Dordelly, hoy desaparecido, la escasez de presupuesto fue una constante desde la fundación oficial del CENIDIM hasta el primer decenio del presente siglo. ${ }^{3}$ En años recientes la situación tampoco ha mejorado. Hace cuatro años, su entonces directora, Yael Bitrán, publicó un artículo titulado "La investigación musical: la experiencia mexicana". En ese escrito, señala que las limitaciones de presupuesto "han puesto freno a ciertos proyectos e iniciativas" (Bitrán, 2016, p. 142) mermando en las labores del centro. El diagnóstico que hace un año presentó el actual director del CENIDIM, Víctor Barrera (2019), publicado en una página del INBAL en Internet, es sintomático, pues deja ver problemas de infraestructura ligados a la escasez de recursos, los cuales se reflejan en la productividad investigativa y el rendimiento en la documentación del patrimonio que se custodia. La Coordinación de documentación, por ejemplo, no puede permitirse programar metas a largo plazo porque dependen de los recursos susceptibles a obtenerse semestre con semestre; no cuenta con bases de datos ni licencias de software especializado para el registro de colecciones o servidores para almacenamiento de información. Por su parte, "cada uno de los investigadores debe conseguir por su cuenta las herramientas necesarias para llevar a cabo sus labores" (Barrera, 2019, p. 20) y tampoco hay un programa editorial que dé salida a sus publicaciones. Pero quizá el tema más grave es el concerniente a los acervos documentales: el Centro se encuentra en el séptimo piso de una torre de investigación y alberga un peso estimado de 10 toneladas de acervos, situación que urge la reubicación de las áreas de documentación.

La situación del CENIDIM ha sido muy similar en las instancias que se dedican a la investigación etnomusicológica en el INAH, la DGCPIU y el INPI, por lo que sería aquí un tanto reiterativo abundar en ello: en los últimos veinte años el apoyo financiero a estos espacios de investigación ha dependido de los vaivenes de la política cultural del Estado y en general, pocas veces ha sido consistente, apenas alcanzando para mantener sus actividades básicas. Pero el desarrollo de la investigación etnomusicológica no solo se relaciona con el apoyo financiero otorgado a las instancias que le auspician, sino fundamentalmente con el grado de legitimidad que ha podido conseguir este quehacer en el ámbito académico de las instituciones en las que se promueve. Podría parecer un tanto esquemático, pero una manera eficaz de sopesar la importancia de la investigación etnomusicológica en estas instituciones es identificando el número de plazas (o puestos) de tiempo completo que se asignan a esta actividad en cada instituto.

${ }^{3}$ Entrevista personal a Hiram Dordelly el 11 de abril de 2008 en el Centro Nacional de Centro Nacional de Investigación, Documentación e Información Musical Carlos Chávez. 
De acuerdo con los datos de su página de Internet, el CENIDIM cuenta actualmente con veintidós investigadores musicales en su planta de investigación, sin embargo, solo tres de ellos se dedican a proyectos de orden etnomusicológico (proyectos relativos a la catalogación de instrumentos musicales, la canción mexicana, y, paisajes sonoros del occidente de México). Si bien los orígenes del CENIDIM remiten directamente al estudio de la llamada música de tradición oral, el quehacer investigativo del Centro en los últimos veinte años se ha orientado casi exclusivamente a los temas tradicionales de la Musicología Histórica. El poco interés que el CENIDIM dedica a la investigación etnomusicológica aunado a la escasez presupuestaria mantiene a dicho quehacer en condiciones precarias.

El caso del Instituto Nacional de Antropología e Historia no es tan distante. El INAH cuenta con 897 plazas de investigación de tiempo completo dedicadas a las distintas ramas del saber antropológico e histórico. De esa totalidad, sólo seis plazas están asignadas a investigadores que se dedican de tiempo completo a la investigación etnomusicológica. La Subdirección de Fonoteca del INAH, donde se encuentran cinco de estas plazas de investigación, dedica la mayor parte de su presupuesto a la divulgación y documentación. Es claro que en ambas instituciones hay una pobre valoración de la investigación etnomusicológica. En el caso del INAH, esto se debe principalmente a la hegemonía de una visión arqueológica, donde lo musical es visto como una rama menor del estudio etnológico; en el caso del CENIDIM/INBAL, prevalece una supuesta primacía de legitimidad del estudio de la "música culta" frente al estudio de la "música tradicional/ popular".

Por su parte, la Dirección General de Culturas Populares, Indígenas y Urbanas mantuvo de manera oficial la investigación etnomusicológica hasta finales del siglo XX, empero, hace unos veinte años esa actividad comenzó a declinar hasta desaparecer por completo alrededor de 2010, como me lo comunicaron dos de sus antiguos investigadores. ${ }^{4}$ En la última década, el fomento a la investigación musical se limitó a lo que las Unidades Regionales y las iniciativas auspiciadas por el Programa de Apoyo a las Culturas Populares y Comunitarias pudieron ofrecer. Como lo asienta la página de Internet de esta Dirección, en los próximos años la Dirección de Culturas Populares enfatizará pragmáticamente en la promoción y difusión de la cultura indígena mediante talleres, conciertos y festivales nacionales, pero difícilmente resucitará la investigación etnomusicológica: desde hace dos

${ }^{4}$ Entrevista personal a Max Jardow Pedersen el 3 de noviembre de 2005 en el Instituto Nacional de Antropología e Historia; entrevista personal a Guillermo González el 21 de enero de 2013 en el Museo Nacional de Culturas Populares. 
décadas no hay una sola plaza de investigación dedicada a ello. Es de notar que esta Dirección es el llamado "punto focal" nombrado por el gobierno mexicano para ser el interlocutor con el Comité Intergubernamental para la Salvaguardia del Patrimonio Cultural Inmaterial de la UNESCO en todo lo relativo a este tipo de patrimonio, sin embargo, el programa de Patrimonio Cultural Inmaterial y Diversidad Cultural de la Dirección de Culturas Populares carece de programas de investigación en torno al tema de la salvaguardia.

En lo que respecta al Instituto Nacional de los Pueblos Indígenas, esta instancia del Estado vive actualmente un proceso de reestructuración al pasar a convertirse en 2018, por mandato presidencial, en un instituto nacional, pues anteriormente se conformaba como Comisión Nacional de los Pueblos Indígenas (CDI). En el seno de esta institución se mantuvo desde los años setenta una Fonoteca y un Departamento de Etnomusicología, sin embargo, de acuerdo con el exdirector de este Departamento, Julio Herrera, en los últimos veinte años estos dos espacios contaron paulatinamente con menos recursos afectando su productividad. ${ }^{5}$ Actualmente, en esta transformación de Comisión a Instituto, el Departamento de Etnomusicología y la Fonoteca Henrietta Yurchenco en apariencia seguirán vigentes, aunque con un perfil prácticamente enfocado a la divulgación y documentación del acervo. En otros tiempos la investigación etnomusicológica de esta institución fue punta de lanza en este campo de estudios, sin embargo, en la actualidad prácticamente se ha extinguido, pues no hay plazas destinadas a la investigación etnomusicológica.

Por último, en la Universidad Nacional Autónoma de México la escasez de espacios de investigación musical es sorprendente. Al interior de la UNAM, el Instituto de Investigaciones Estéticas es el único que cuenta con plazas de tiempo completo de investigación musical. De acuerdo con su página de Internet, dicho Instituto cuenta en total con 74 investigadores, sin embargo, únicamente cuatro se dedican a investigar la música, y de entre ellos, solo uno trabaja temas etnomusicológicos desde 2015. En los demás institutos de la UNAM la investigación musical apenas es perceptible. En el Instituto de Investigaciones Antropológicas, desde 2001, un investigador de tiempo completo trabaja colateralmente temas etnomusicológicos, alternando este quehacer con su proyecto central de orden lingüístico. En 2012, en el Instituto de Investigaciones Sociales de la UNAM, una investigadora concursó y ganó una plaza de investigación con un proyecto centrado en patrimonio musical que ha mantenido hasta hoy y con el cual abrió brecha en ese instituto donde no se realizaba investigación

${ }^{5}$ Entrevista personal a Julio Herrera el 22 de julio de 2015 en la emisora radiofónica La Voz de los Tres Ríos, en Etchojoa, Sonora. 
musical. A ellos se suman otras dos plazas y media, pero de docencia, en la Licenciatura en Etnomusicología, donde colateralmente se hace investigación en el marco de las labores docentes. Aunque en la UNAM el renglón de recursos económicos es distinto, pues generalmente ha contado con un presupuesto suficiente para sus áreas de investigación, es evidente que la valoración de la investigación etnomusicológica en la UNAM es exigua.

En suma, puede verse que en los últimos veinte años la investigación etnomusicológica entró en un paulatino estado de declive, pues los espacios institucionales que antes apoyaban esta labor ahora la han casi omitido. Sin duda, el problema de los recursos económicos ha intervenido propiciando esta situación, pero igualmente importante es otra contrariedad que complejiza el tema y que tiene que ver con la falta de legitimidad académica del campo etnomusicológico tanto en el ámbito de las humanidades como en el de las ciencias sociales. Incluso suponiendo que no hubiera carencia de recursos económicos, probablemente este quehacer seguiría siendo relegado al interior de los ámbitos antropológico y musical. Como ya lo mencionaba más arriba, son varios los factores que podrían explicar esta situación, pero quizá uno de los más importantes tiene que ver con la estigmatización/estereotipación de este campo de estudio, el cual sigue siendo vinculado con el antecedente utilitario de los estudios de folklore en periodos formativos de las instituciones culturales del Estado mexicano. Esto se refleja principalmente en las instituciones más cercanas al orden antropológico como el INAH, el INPI y la DGCPI. Otro factor más que podría dar razón de esta posición marginal disciplinar se vincula con un criterio epistemológico y de clase en relación a la valoración de la investigación etnomusicológica. Si bien es cierto que desde hace algunos años la división tajante entre musicología histórica y etnomusicología ha tendido a relajarse, sigue prevaleciendo una perspectiva académica que distingue "clases" entre temáticas de estudio, la cual sigue jerarquizando tácitamente a la cultura popular como "baja cultura". En buena medida esa perspectiva ha determinado su poca presencia (plazas de investigación) en el ámbito musical del CENIDIM y la UNAM. Como sea, esta insuficiente legitimidad académica entrelazada a la falta de recursos colabora a mantener en situación precaria el quehacer etnomusicológico en las instituciones del Estado.

\section{La investigación etnomusicológica y sus perspectivas en el escenario actual}

En el marco del panorama presentado es pertinente preguntarse: ¿qué perspectivas se vislumbran para la investigación etnomusicológica en la 
nueva coyuntura de cambio de régimen de gobierno en México? Sin duda, a partir del 2018, con la llegada al poder de uno de los partidos políticos que presumía ser de izquierda, México vislumbraba un tiempo de profundos cambios que incidieran en la sociedad y en la propia configuración del Estado mexicano. Las políticas neoliberales de las últimas tres décadas intensificaron graves problemas nacionales como los conflictos territoriales y socioambientales, proyectos extractivistas, reformas laborales, educativas y energéticas, pobreza, marginación y desigualdad, inseguridad, violencia de género, entre otros. En ese contexto, era de suponer que para transformar al país debía ser fundamental el sector cultural como importante eje de recuperación del tejido social y pacificación del país, como lo planteaba el discurso que manejó el partido Movimiento Regeneración Nacional para llegar al poder.

Sin embargo, al inicio de la administración del nuevo régimen pronto se dejó ver que el tema de la insuficiencia presupuestal para este sector no cambiaría. El nuevo gobierno comenzó su gestión en 2019 reduciendo en $3.9 \%$ el presupuesto asignado a la Secretaría de Cultura con respecto a 2018 (Diario Oficial de la Federación, 18-01-2019). El gobierno se justificó señalando que las reducciones se aplicarían en el plano administrativo y no en las tareas sustantivas, de acuerdo con la promulgada Ley Federal de Austeridad Republicana (Cámara de Diputados, 2019); sin embargo, se volvía a repetir la precariedad permanente en la que el sector cultura había sobrevivido durante los anteriores gobiernos neoliberales: desde hace más de diez años, el presupuesto cultural no supera el $0.2 \%$ del Producto Interno Bruto (Amador, 2019). Como era de esperar, esta situación generó amplio descontento en numerosos miembros de la comunidad artística y cultural. Luego de las protestas, se agregó otra cantidad al presupuesto, pero destinada exclusivamente al Programa de Apoyos a la Cultura (S268), que comprende el Apoyo a las Culturas Municipales y Comunitarias (PACMYC), Apoyo a la Infraestructura Cultural de los Estados (PAICE) y Apoyo a Festivales Culturales y Artísticos (Profest).

Desafortunadamente, el sector cultura ha sido el "eje transformador" más relegado del actual gobierno, pues para junio de 2019 no había todavía diagnósticos culturales, ni un Plan Nacional de Cultura, y en el Plan Nacional de Desarrollo lo concerniente a política cultural apenas se menciona de manera escueta (Diario Oficial de la Federación, 12-07-2019). Quizá por ello en el informe del Primer año de gobierno del año pasado, de unas 22 cuartillas de extensión, se le dedicó solo un párrafo de cinco líneas al sector cultural (Gobierno de México, 2019). Durante el presente año, la situación no cambió pues para 2020 el presupuesto cultural solo se incrementó en 
0.7\%, lo cual calificó como "inercial" apenas cubriendo la tasa de inflación (Cámara de diputados, 2020). En el caso de algunas instituciones como al Instituto Nacional de los Pueblos Indígenas (INPI) les fue recortado más del 33\% del presupuesto (Miranda, 2020), lo que puso en duda el discurso oficial en torno a la especial atención que se otorgaría a los Pueblos Indígenas de México (INPI, 2018).

Recientemente, la pandemia por COVID-19, que en México obligó al confinamiento desde fines de marzo de 2020, propició condiciones económicas que han llevado al sector cultural a un panorama desalentador. A inicios de ese mismo mes se anunció un decreto presidencial que extinguía varios fideicomisos relacionados con el sector cultural, entre los que estaba el Fideicomiso para el Fomento y la Conservación del Patrimonio Cultural Antropológico, Arqueológico e Histórico de México, y que era de especial importancia para el INAH. Durante ese mismo mes, en plena cuarentena, otro decreto ordenaría a todas las dependencias de la administración pública federal no ejecutar el $75 \%$ del presupuesto de gasto operativo disponible para el resto del año con miras a hacer frente a las consecuencias sanitarias y económicas ocasionadas por la pandemia (Diario Oficial de la Federación, 23-04-2020). Las protestas del sector científico y cultural no se dejaron esperar, pero solo algunas dependencias como los centros de investigación públicos del Consejo Nacional de Ciencia y Tecnología (CONACYT), lograron ser exceptuados del drástico recorte (El Universal, 01-06-2020). Esta reducción, de mantenerse, pondría en condiciones críticas a las instituciones culturales del Estado, pues, entre otros aspectos, las disposiciones incluyen que no habrá nuevas contrataciones. En el caso específico del INAH, esta política repercute en nuestra área de estudio no solo en la ausencia de presupuesto para los proyectos en curso, sino en la posible pérdida de dos plazas de investigación musical que estaban en proceso de abrirse a concurso. ${ }^{6}$

Si bien parece paradójico pretender transformar al país prescindiendo del sector cultural, todo indica que por ahora éste tendrá poca participación, pues la grave situación económica de las instituciones del Estado así lo condiciona. Ahora, pese a este adverso panorama, algunos indicios sugieren posibles alternativas para las investigaciones etnomusicológicas. Aunque gran parte de este quehacer durante el siglo XX se realizó en las instituciones nacionales dirigidas desde la capital del país (INBA, INAH, INPI, UNAM,

\footnotetext{
${ }^{6}$ No obstante a estas condiciones sorprende la postura del Estado de continuar con proyectos infraestructurales de gran envergadura (con fuerte inversión de la iniciativa privada) como el llamado Tren Maya, el Corredor Interoceánico, el Aeropuerto de Santa Lucía y la Refinería de Dos Bocas, que no han prosperado exentos de polémica y el rechazo de ciertos sectores sociales.
} 
DGCPIU), el esquema centralista ha ido paulatinamente cambiando. Por fortuna, desde inicios del presente siglo, distintos "polos etnomusicológicos" han emergido ganando espacios en importantes universidades o instancias de investigación estatales. ${ }^{7}$ Hasta ahora puede identificarse la emergencia de al menos siete polos en el interior de la República, en los que por lo menos un(a) investigador(a) o más, cuenta con una plaza de tiempo completo dedicada prioritariamente a cuestiones etnomusicológicas, incluso con seminarios o grupos de trabajo.

En la región noroeste, cuatro instancias conforman uno de estos "polos": la Universidad Autónoma de Baja California, El Colegio de la Frontera Norte, la Universidad de Sonora y la Escuela Nacional de Antropología e Historia del Norte de México. En el noreste del país la Universidad Autónoma de Zacatecas y el Centro de Investigaciones y Estudios Superiores en Antropología Social (Noreste) constituyen otro polo. Un nodo más, en la región del Bajío, lo integran investigadores de la Universidad Autónoma de San Luis Potosí y la Universidad de Guanajuato. En la región Occidente uno de los primeros "polos" del interior del país lo fraguaron El Colegio de Michoacán y la Universidad de Guadalajara, que hoy son acompañados y consolidados también por la Universidad Michoacana de San Nicolás de Hidalgo y el Instituto Tecnológico y de Estudios Superiores de Occidente. En la región del Golfo, la Universidad Veracruzana y el Instituto Veracruzano de Cultura constituyen otro polo, mientras que más al sur, en el estado de Oaxaca, el Centro de Investigaciones y Estudios Superiores en Antropología Social (Pacífico Sur) y la sede regional del Instituto de Investigaciones Estéticas de la UNAM apuntalan un polo más. En el sureste del país, la Universidad de Ciencias y Artes de Chiapas consolida otro polo de investigación etnomusicológica, contiguo con uno más en la Península de Yucatán donde hay actividad en este campo de estudios en la Universidad Autónoma de Yucatán.

Si a este surgimiento de "polos" estatales agregamos el acierto actual del Estado mexicano de incrementar los recursos para la infraestructura cultural de los estados mediante el Programa Apoyo a la Infraestructura Cultural de los Estados (PAICE), es de esperar que las instituciones estatales de cultura incrementen su actividad y con ello, posiblemente, el apoyo a la investigación de las músicas tradicionales y populares. Afortunadamente, desde hace más de tres lustros el quehacer disciplinar gravitó hacia los estados de la República donde el trabajo de numerosos investigadores

\footnotetext{
${ }^{7}$ De hecho, es posible estimar que desde hace unos quince años por lo menos la mitad de los resultados de investigación del campo de estudios sobre músicas tradicionales y música popular provienen de proyectos adscritos a las entidades estatales.
} 
adscritos a centros de investigación y universidades estatales, así como de algunos investigadores independientes ha mantenido activo el campo de estudios musicales. Sin duda este reciente desarrollo muestra que la investigación musical se ha diversificado ganando poco a poco espacios en instancias universitarias que atienden una importante ausencia en la historia del campo. Los "polos" estatales son la veta más prometedora del campo de estudios musicales en la actualidad.

\section{Conclusiones}

En el presente artículo argumento que en México la investigación etnomusicológica ha ocupado un lugar marginal en las instituciones nacionales debido a su relación con los intereses de la política cultural del Estado. Dicho vínculo, susceptible a los vaivenes políticos de diferentes momentos históricos, ha propiciado una falta de reconocimiento académico de este campo de estudio, y la subsecuente escasez de recursos y espacios laborales que merman su óptimo desarrollo. Es probable que esta situación sea similar en otros países de América Latina, donde la falta de apoyo económico de parte del Estado haya ido de la mano con un escaso reconocimiento académico del quehacer etnomusicológico, teniendo que pugnar en consecuencia por afrontar de manera simultánea este doble desafío.

La investigación etnomusicológica institucional enmarcada en un sector (cultura) que tiende a ser poco valorado por las políticas de desarrollo enfrenta hoy condiciones muy adversas. Si bien con el reciente cambio de régimen de gobierno se esperaban grandes transformaciones sociales y una mejora significativa para el sector cultural, éste fue relegado desde el comienzo de la presente administración, situación que se agravó tras la crisis económica que trajo la pandemia por COVID-19, por lo que no parece viable prever mejora en las instituciones de cultura federales. No obstante, con el gradual fortalecimiento de la autonomía de los estados de la federación y la emergencia paulatina de "polos" de investigación musical en el seno de universidades y centros de investigación estatales, es posible avizorar alternativas para el campo de estudio allende la esfera de las instituciones nacionales. Dado que la emergencia de estos "polos" ha obedecido en gran medida a una diversidad disciplinar propia del actual desarrollo de la investigación musical (más que a políticas institucionales), el papel que juega el esfuerzo personal y el trabajo individual de investigadoras e investigadores sigue siendo fundamental en la construcción de un camino más prometedor para nuestro campo de estudios. 
En general es comprensible, pero no justificable, la falta de atención de las instituciones educativas y de cultura a este saber disciplinar. Quizá también debido a que las investigaciones etnomusicológicas en México han tendido a priorizar la producción de conocimiento que pondera la extraordinaria diversidad cultural del país -más que a atender necesidades sociales en un sentido "aplicado"-, es que los alcances de este campo de estudios han sido percibidos limitadamente, tanto en el sector académico como en el diseño de políticas culturales nacionales. Si bien es muy importante aportar conocimiento para la valoración y respeto a la diferencia cultural, actualmente son muchas otras las vertientes en que las investigaciones etnomusicológicas pueden colaborar a afrontar algunos de los problemas sociales más sensibles que se viven hoy en México. En el orden de una etnomusicología aplicada pueden mencionarse varios ejemplos. Uno de ellos es el estudio de las relaciones de poder e inequidades económicas que se producen en el vínculo entre patrimonio musical y turismo, así como en las concepciones de sustentabilidad cultural y desarrollo. Otro, es el tema de la violencia en el campo social y cultural, tanto vinculada con el narcotráfico, como con los feminicidios y las relaciones intrafamiliares. Las investigaciones etnomusicológicas podrían ahondar en advertir cómo la violencia se encuentra inmersa y apologizada en repertorios fuertemente arraigados en el gusto musical, y cómo, en contraposición, la música y la práctica musical puede sumarse a los proyectos que busquen ofrecer otras opciones que breguen por una cultura de respeto y paz. Un tema más tiene que ver con el posible papel de la música en relación a la salud pública: el potencial de la música como colaboradora en la rehabilitación de adicciones, la prevención de suicidios, la difusión de programas de salud o la regulación de la polución sonora en las ciudades. Por su parte, las investigaciones musicales podrían también aportar en una diversidad de temas relacionados con cuestiones educativas: prevenir la discriminación y el racismo; coadyuvar al reconocimiento social de minorías étnicas; colaborar al diseño de programas escolares interculturales, entre otros. En fin, en el contexto actual, el estudio de las prácticas y expresiones musicales puede ofrecer conocimiento que ayude no solo a mejorar la calidad de vida de los seres humanos, sino a mejorarnos como seres humanos. 


\section{Bibliografía}

» Barrera, V. (2019). Proyecto para la dirección del CENIDIM 2019-2023. Página Web de la Subdirección General de Educación e Investigación Artísticas del INBA. Recuperado de https://sgeia.bellasartes.gob.mx/ archivos/convocatorias/auscultacion/cenidim_vbg_proyecto.pdf

" Bitrán, Y. (2016). Investigación musical: la experiencia mexicana. En Y. Bitrán y C. Rodríguez (Coords.). Perspectivas y desafíos de la investigación musical en Iberoamérica (pp. 129-143). México: Secretaría de Cultura-Secretaría General Iberoamericana-Instituto Nacional de Bellas Artes. Recuperado de https://www.segib.org/wp-content/uploads/memorias_I_coloquio.pdf

"Cortéz, L. J. (2016). Primeros bocetos para una biografía del CENIDIM. En Y. Bitrán y otros (Coords.). Cuarenta años de investigación musical en México a través del CENIDIM (pp. 43-53). México: Centro Nacional de Investigación, Documentación e Información Musical Carlos Chávez. Recuperado de https://www.researchgate.net/publication/307466816_Cuarenta_anos_de_ investigacion_musical_en_Mexico_a_traves_del_Cenidim

»Flores, G. (2014). Y con la pirekua ni siquiera nos preguntaron... La declaración de la pirekua como Patrimonio Cultural Inmaterial de la Humanidad: una perspectiva crítica. Diario de campo, 2, 32-38. Recuperado de https://www.revistas.inah.gob.mx/index.php/diariodecampo/article/ view/5596/6441

» García, M. A. (2016). La (etno)musicología, el neoliberalismo y el silencio de las instituciones. El oído pensante, 4(2), 1-2. Recuperado de http://ppct. caicyt.gov.ar/index.php/oidopensante/article/view/9391/9058

» Martínez, J. A. (2017). Del dicho al hecho... Una valoración de la declaratoria de la UNESCO y los mariachis. En L. Ku (Coord.). El mariachi. Bailes y huellas (pp. 289-306). Jalisco: El Colegio de Jalisco-Secretaría de Cultura-Gobierno del Estado de Jalisco.

» Ruiz, C. (2015). Reflexiones sobre la historia de la etnomusicología en México. Colección de Conferencias Magistrales Beatriz Barba de Piña Chan. México: Instituto Nacional de Antropología e Historia.

»Sevilla, A. (2014). Del ritual al espectáculo. Diario de campo, 2, 2431. Recuperado de https://www.revistas.inah.gob.mx/index.php/ diariodecampo/article/view/5591/6435

"Toussaint, E. (2006). Banco Mundial: el golpe de Estado permanente. Quito: Editorial Abya-Yala. Recuperado de http://www.cadtm.org/IMG/pdf/banco_ mundial_abya_yala_ecuador.pdf 


\section{Otras fuentes consultadas}

" Amador, J. (2019). Presupuesto cultural 2020: el esquema de siempre. Proceso. Recuperado de https://www.proceso.com.mx/609771/ presupuesto-cultural-2020-el-esquema-de-siempre

»Cámara de Diputados del Honorable Congreso de la Unión (2019). Ley Federal de Austeridad Republicana. Recuperado de http://www.diputados. gob.mx/LeyesBiblio/pdf/LFAR_191119.pdf

》 Cámara de Diputados del Honorable Congreso de la Unión. (2020). Presupuesto de egresos de la Federación para el ejercicio fiscal 2020. Recuperado de http:// www.diputados.gob.mx/LeyesBiblio/pdf/PEF_2020_111219.pdf

»Diario Oficial de la Federación (DOF). (8 de enero de 2019). Calendario de Presupuesto asignado al Ramo 48 Cultura para el ejercicio fiscal 2019. Recuperado de https://www.dof.gob.mx/nota_detalle.php?codigo=5548407 \&fecha $=18 / 01 / 2019$

»Diario Oficial de la Federación (DOF). (12 de julio de 2019). Plan Nacional de Desarrollo 2019-2024. Recuperado de https://www.dof.gob.mx/nota_ detalle.php?codigo $=5565599$ \&echa $=12 / 07 / 2019$

»Diario Oficial de la Federación (DOF). (23 de abril de 2020). Decreto por el que se establecen las medidas de austeridad que deberán observar las dependencias y entidades de la Administración Pública Federal. Recuperado de https://dof. gob.mx/nota_detalle.php?codigo $=5592205 \&$ fecha $=23 / 04 / 2020$

»El Universal (2020). Centros públicos de Investigación fuera del recorte de 75\%. Recuperado de https://www.eluniversal.com.mx/ciencia-y-salud/ ciencia/centros-publicos-de-investigacion-fuera-del-recorte-de-75-cide

》 Gobierno de México (2019). Primer Informe Gobierno de México 2018-2019. Recuperado de https://www.gob.mx/primerinforme

» Instituto Nacional de los Pueblos Indígenas (INPI) (2018). Programa Nacional de los Pueblos Indígenas 2018-2024. Recuperado de https://www. gob.mx/inpi/es/articulos/programa-nacional-de-los-pueblos-indigenas2018-2024-mexico-185839?idiom=es

»Miranda, F. (2020). Piden a AMLO desde Oaxaca reasignar más recurso al INPI. El Universal. Oaxaca. Recuperado de https://oaxaca.eluniversal. com.mx/politica/06-01-2020/piden-amlo-desde-oaxaca-reasignar-masrecursos-al-inpi

\section{Biografía / Biografia / Biography}

\section{Carlos Ruiz Rodríguez}

Nacido en Ciudad de México, es Maestro en Etnomusicología y Doctor en Antropología por la Universidad Nacional Autónoma de México. Labora 
como Profesor-investigador titular para el Instituto Nacional de Antropología e Historia y es también docente en la Licenciatura en Etnomusicología de la Universidad Nacional Autónoma de México. Ha realizado investigaciones en torno a las tradiciones musicales afromexicanas, la organología mexicana, el desarrollo histórico de la etnomusicología y la salvaguardia del patrimonio musical en México. Es autor de un libro y una veintena de artículos y capítulos publicados en diversas ediciones académicas. Es miembro del Sistema Nacional de Investigadores del Consejo Nacional de Ciencia y Tecnología, y funge como "agente de enlace" de México ante el ICTM. 